\section{Diagnosis of brain death}

\section{Calixto Machado}

Institute of Neurology and Neurosurgery, Department of Clinical Neurophysiology, Havana, Cuba

\section{Abstract}

Brain death (BD) should be understood as the ultimate clinical expression of a brain catastrophe characterized by a complete and irreversible neurological stoppage, recognized by irreversible coma, absent brainstem reflexes, and apnea. The most common pattern is manifested by an elevation of intracranial pressure to a point beyond the mean arterial pressure, and hence cerebral perfusion pressure falls and, as a result, no net cerebral blood flow is present, in due course leading to permanent cytotoxic injury of the intracranial neuronal tissue. A second mechanism is an intrinsic injury affecting the nervous tissue at a cellular level which, if extensive and unremitting, can also lead to BD. We review here the methodology of diagnosing death, based on finding any of the signs of death. The irreversible loss of cardio-circulatory and respiratory functions can cause death only when ischemia and anoxia are prolonged enough to produce an irreversible destruction of the brain. The sign of such loss of brain functions, that is to say BD diagnosis, is fully reviewed.

\section{Introduction}

Long before modern technology, everyone agreed that death occurred when heartbeat and breathing ceased, and the soul abandoned the body. Nonetheless, a new concept of death evolved as technology progressed, forcing medicine and society to redefine the ancient cardio-respiratory diagnosis to a neurocentric diagnosis of death. ${ }^{1.4}$ In the meantime, the technical and scientific advances of the last century provided effective mechanical ventilators, and cardiopulmonary resuscitation ("reanimation") compelled physicians in the late 1950s to confront a condition impossible even to imagine previously, a state in which the brain is massively damaged and nonfunctional while other organs remain functioning. Was such a patient alive or dead? This radically changed the course of the debates about human death, marking a turning point when brain-oriented definitions of death started to be formulated, and brain death (BD) was gradually accepted as death of the individual. ${ }^{5-12}$ However, it is commonly believed that the con- cept of BD evolved to benefit organ transplantation. A historical approach demonstrates that both brain death and transplantation had fully separate origins. Organ transplantation became possible with technical advances in surgery and immunosuppressive treatment. The concept of BD evolved with the introduction of intensive care units. ${ }^{12,13}$

BD should be understood as the ultimate clinical expression of a brain catastrophe leading to a complete and irreversible neurological stoppage, characterized by irreversible coma, absent brainstem reflexes, and apnea. ${ }^{14}$ Most authors affirm that the diagnosis of BD is just a clinical assessment, and after the Harvard Committee Report, ${ }^{15,16}$ most countries and states designed their BD diagnostic criteria. ${ }^{6,717-21}$ BD diagnosis should be carried out following a certain set of principles; that is to say, excluding major confusing factors, establishing the cause of the coma, determining irreversibility, and precisely testing brainstem reflexes at all levels of the brainstem. ${ }^{22}$

\section{Pathophysiology of brain death}

Increased intracranial pressure (ICP) is considered the most important pathophysiological mechanism of BD leading to a complete cessation of intracranial blood flow. Upholding of oxygenation and hemodynamics by vasopressor drugs as well as mechanical ventilation can sustain somatic organs while the brain suffers an ongoing necrosis process. However, this is not the only pathophysiological mechanism of BD. ${ }^{1,23}$ Palmer and Bader studied a series of brain-dead patients by brain tissue oxygenation $\left(\mathrm{PbtO}_{2}\right)$ and described two pathophysiological patterns regarding cerebral blood flow (CBF). ${ }^{23,24}$ The most common pattern is manifested by an elevation of ICP to a point beyond the mean arterial pressure (MAP), and hence cerebral perfusion pressure (CPP) falls to zero and, as a result, no net CBF is present, in due course leading to permanent cytotoxic injury of the intracranial neuronal tissue.

In addition, there may be circumstances where an ICP increment does not lead to CBF cessation. This may occur when ICP augmentation is compensated in infants with open fontanelles and soft, deformable skulls, and in patients whose skulls are open owing to multiple fractures, ventricular drainage, or decompressive craniectomy. ${ }^{25-35}$ Moreover, diffuse intracranial parenchymal swelling is the main reason for a markedly elevated ICP, but swelling is not an indefinite phenomenon, and it may decrease progressively, and if MAP is maintained at reasonable values, $\mathrm{CBF}$ might ultimately return. ${ }^{25,28}$

The second pattern described by Palmer and
Correspondence: Calixto Machado, Institute of Neurology and Neurosurgery, 29 y D, Vedado, La Habana 10400, Cuba.

E-mail: braind@infomed. sld.cu

Key words: brain death, signs of death, brain death criteria, transcranial Doppler, EEG, multimodality evoked potentials, CT angiography.

Conflict of interest: the author reports no conflicts of interest.

Received for publication: 11 September 2009.

Revision received: 14 December 2009.

Accepted for publication: 20 January 2010.

This work is licensed under a Creative Commons Attribution 3.0 License (by-nc 3.0).

(C) Copyright C. Machado 2010

Licensee PAGEPress, Italy

Neurology International 2010; 2:e2

doi:10.4081/ni.2010.e2

Bader is characterized by preserved CBF, because normal ICP does not exceed MAP, and sufficient CPP is maintained leading to CBF preservation, which supplies the nervous tissue with necessary oxygen, glucose, and nutrients to permit its survival. ${ }^{24}$ In this pattern the mechanism causing $\mathrm{PbtO}_{2}$ to fall to zero is an intrinsic catastrophe affecting the nervous tissue at a cellular level which, if extensive and unremitting, can also lead to $\mathrm{BD} .^{23,25,36}$ It is clear that in this pattern the lack of oxygenation of the brain is not a failure of the delivery system, and hence it stands for end organ breakdown of the brain at the capillary or tissue level. ${ }^{23,36}$

\section{Diagnosis of brain death}

BD diagnosis should be carried out following a certain set of principles; ${ }^{6,21,3746}$ that is to say, excluding major confusing factors, establishing the cause of the coma, determining irreversibility, and precisely testing brainstem reflexes at all levels of the brainstem. ${ }^{47}$ Nonetheless, most criteria for BD diagnosis do not mention that this is not the only way of diagnosing death. If a concept of death on neurological grounds is accepted, then BD diagnostic criteria can be applied only in patients under life support assistance in ICUs. Does it mean that when a physician diagnoses death in a regular ward (the patient is not under life support), applying cardio-circulatory and respiratory diagnostic criteria, or when a forensic specialist diagnoses death in a body under criminal circumstances, we are denying a brain-oriented concept of death? ${ }^{1,48}$

Recently Cuba has passed a law for the determination and certification of death. The National Commission for the Determination 
and Certification of Death has accepted a neurological view of death and emphasized that any legislation of death should be completely separated from any norm governing organ transplants. ${ }^{49.52}$ Hence, the Commission enumerated three possible situations for diagnosing death:

i) Outside the intensive care environment (without life support), physicians apply the cardio-circulatory and respiratory criteria.

ii) In forensic medicine circumstances, physicians utilize cadaveric signs. (They do not even need a stethoscope.)

iii) In the intensive care environment (with life support) when cardio-circulatory and/or respiratory arrest occurs, physicians utilize the cardio-circulatory and respiratory criteria. When physicians suspect an irreversible loss of brain functions in a heart-beating and ventilatory supported case, BD diagnostic criteria are applied.

This methodology of diagnosing death, based on finding any of the signs of death, is not related to the concept that there are different types of death. The irreversible loss of cardio-circulatory and respiratory functions can cause death only when ischemia and anoxia are prolonged enough to produce an irreversible destruction of the brain. According to the Commission, there is only one kind of death, based on the irreversible loss of brain functions. ${ }^{1,48.52}$

\section{Signs of death}

The diagnosis of death was based on the finding of any of the following signs of death:

I Irreversible loss of respiratory function.

II Irreversible loss of cardio-circulatory functions.

III Algor mortis (postmortem coldness).

IV Livor mortis (postmortem lividity).

V Rigor mortis (postmortem rigidity).

VI Cadaveric spasm.

VII Loss of muscle contractions.

VIII Putrefaction.

IX Irreversible loss of brain functions.

Signs I and II correspond to the classical respiratory and cardio-circulatory functions. Signs III to VIII are related to forensic circumstances, and beyond the scope of this review.

\section{Irreversible loss of brain functions (diagnosis of brain death)}

As has already been emphasized, when physicians suspect an irreversible loss of brain functions in a heart-beating and ventilatory supported case, BD diagnostic criteria are applied. To assess brain functions during BD diagnosis, the clinical neurological examination is the accepted standard. . $^{8,12,13,22,48,52-54}$

\section{Preconditions or pre-requisites}

1. Coma owing to irreversible acute brain damage of known etiology, affecting both hemispheres and brainstem. What is demanded is to have clear and definite clinical and/or neuroimaging evidence of an acute central nervous system (CNS) insult that is consistent with the irreversible loss of neurological function. ${ }^{1,7,22,77,55}$

2. At the time of beginning the neurological examination, it is essential to exclude confounding factors that mimic BD:1,22,56,57

Unresuscitated shock. This is indispensable to applied BD criteria only when blood pressure has a minimum value of $90 \mathrm{~mm} \mathrm{Hg.}{ }^{22,58-62}$ Hypothermia (core temperature $<34^{\circ} \mathrm{C}$ ). An inability to regulate temperature, or poikilothermia, is often present in BD. Core temperature results should be obtained through central blood, rectal, esophageal, or gastric measurement. Most sets of criteria for BD diagnosis demand a body temperature of at least $32.2^{\circ} \mathrm{C}$. $1,17,22,43,55,61-64$

Severe metabolic disorders capable of causing a potentially reversible coma. Severe metabolic or endocrine abnormalities make BD unreliable. ${ }^{22,55575,65}$ Metabolic or endocrine derangement including glucose, electrolytes (including phosphate, calcium, and magnesium), inborn errors of metabolism, liver or renal dysfunction, etc. may cause a potentially reversible coma. ${ }^{1,22}$

Peripheral nerve or muscle dysfunction and neuromuscular blockade potentially play a role in inducing unresponsiveness in patients, and it could be a confounding factor in BD diagnosis. ${ }^{66-72}$

Clinically significant drug intoxications (e.g. alcohol, barbiturates, sedatives, hypnotics).

CNS-depressant drugs should be ruled out if the clinical history is indicative. . $5,72-76^{-1}$ Clinicians in the emergency department are often confronted with coma patients owing to poisoning or intoxication. Several authors recommend using naloxone in a titrated way when an opiate intoxication is suspected. ${ }^{77}$ In the same way, flumazenil has been advocated as a benzodiazepine antagonist in coma of unknown etiology. ${ }^{77,78}$

\section{Diagnostic criteria}

1. Deep unresponsive coma. The diagnosis of deep unresponsive coma demands a comatose patient showing a lack of spontaneous movements in addition to an absence of motor responses mediated by stimuli applied within the cranial nerve distribution. ${ }^{17,22,47,49,53,65}$ CNSmediated motor response to pain in any other distribution, seizures, and decorticate and decerebrate responses impede BD diagnosis. Some brain-dead individuals may present spinal reflexes or motor responses, confined to spinal distribution, which do not preclude the BD diagnosis. $22,55,61,62,79,80$
2. Absent brainstem reflexes. The reflexes mediated by the cranial nerves are main indicators of brainstem function. Hence, to prove their absence is indispensable to BD diagnosis. The individual significance of each brainstem reflex varies in BD diagnosis according to an intrinsic sensitivity of the cranial nerve networks and to the effect of some accompanying factors in brain-dead patients, such as trauma, local edema, dried tissues, and intracranial tubes affecting the exploration of reflexes. ${ }^{17,79}$

Pupillary reflex. This reflex, direct and consensual, is considered one of the most discriminant reflexes in BD diagnosis. ${ }^{17,22,55,57,61,62,79,81}$ Mydriatic, small, or mediumsized pupils are found in brain-dead cases. ${ }^{17,43,63,64}$

Corneal reflex. Unilateral corneal stimulation with a throat swab induces a bilateral closure of the eyelids, is an easy response to elicit and, if present, is readily observed. This is also one of the most discriminant reflexes in BD diagnosis. A bilateral or unilateral response of eyelid closure and upward deviation of the eye (Bell's phenomenon) indicates preserved brainstem functioning. However, edema or drying of the cornea, and severe facial and ocular trauma may preclude a satisfactory stimulus for this reflex. Moreover, the threshold for excitation decreases markedly if the lids are kept closed. . $1,417,22,47,79,82,83$

Oculo-cephalic and oculo-vestibular responses. The oculocephalic reflex, also known as Doll's eyes response, is elicited upon brisk turning of the head from middle position to $90^{\circ}$ on both sides. In comatose patients without lesions of the brainstem, the eyes normally conjugately deviate to the other side. In BD no eye movements are observed. The neural pathways of this reflex are mediated through arcs involving the vestibular mechanisms, medial longitudinal bundle, and ocular nerves. This is a reflex easy to obtain and moderately discriminative. The oculo-vestibular response is elicited by irrigating the tympanum in both sides with iced water. In a comatose patient without lesions of the medial longitudinal bundle, and/or ocular nerves, the elicited response is a slow deviation of the eyes directed to the cold caloric stimulus. The head of the patient should be elevated $30^{\circ}$ above the horizontal plane, and 50 cc of iced water is irrigated into the external auditory canal using a small suction catheter. To confirm lack of eye movement may be very difficult; it has been suggested pen marks are placed on the lower eyelid at the level of the pupil to facilitate the detection of slight eye movements. The examiner should observe for one minute after irrigation, and wait an interval of five minutes before stimulating 
the opposite side. It is essential that the examiner confirm that the external auditory foramen and tympanic membrane are undamaged, because clotted blood or cerumen in the external auditory canal may impair this response. Moreover, a rupture of the eardrum usually augments caloric responses. The presence of severe facial and ocular trauma, eyelid edema, and chemosis of the conjunctiva may limit movement of the globes, making it very difficult to elicit and observe eye movements. Basal fracture of the petrous bone abolishes the caloric response unilaterally and may be identified by the presence of an ecchymotic mastoid process (Battle's sign). There are also some drugs that can lessen this reflex, such as tricyclic antidepressants, aminoglycosides, antiepileptic drugs, anticholinergics, and chemotherapeutic agents, etc. ${ }^{1,68,6,62}$

Gag and cough response. Pharyngeal (gag), cough, and swallowing reflexes are often difficult to explore because of the presence of tubes in the throat and dryness of the mucosa. Hence, in suspected brain-dead cases the cough response is usually explored by passing a catheter through the endotracheal tube and suctioning with negative pressure for several seconds. As these reflexes have their arcs through the medulla oblongata, it is desirable to explore them. ${ }^{17,22,64,84}$

3. Negative atropine test. The atropine test (AtT) assesses bulbar parasympathetic activity on heart activity in brain-dead patients. ${ }^{85}$ Ouaknine first proposed including this as a criterion for the so-called brainstem death. ${ }^{85-89}$ The method for this test consists in injecting 2 mg atropine under continuous monitoring of the ECG during 10 minutes. The AtT is considered negative if heart rate is not augmented by more than $3 \%$ compared with basal ECG records. ${ }^{1,58,86,90-95}$

4. Absent respiratory effort confirmed by the apnea test. The apnea test (AT) has been considered by some authors as the "condition sine qua non" for determining $\mathrm{BD}$, because it provides an essential sign of a definitive loss of brainstem functions. Nonetheless, several authors have expressed their concern about the safety of this procedure, owing to potential complications such as severe hypotension, pneumothorax, excessive hypercarbia, hypoxia, acidosis, cardiac arrhythmia, or asystole, which may constrain the examiner to abort the test, thereby compromising BD diagnosis. Nevertheless, when an appropriate oxygen-diffusion procedure is used, this technique is safe. ${ }^{1,96-105}$

5. Periods of observation. If BD determination is only based on clinical evaluation, the following periods of observation were proposed by the Cuban Commission. ${ }^{1,49-52}$

Six hours at least, if a structural and irre- versible CNS insult can be demonstrated by clinical and neuroimaging evidences.

In cases of acute hypoxic-ischemic brain injury, clinical evaluation should be delayed for 24 hours subsequent to the cardio-respiratory arrest, or an ancillary test could be performed.

Periods of observation can be shortened according to medical criteria by the application of confirmatory tests, to demonstrate a complete cessation of brain circulation, or to demonstrate loss of bioelectrical activity.

\section{Confirmatory tests}

It is widely accepted that BD is a clinical diagnosis, and currently it is defined as a complete and irreversible loss of brain function. Confirmatory laboratory tests are recommended when specific components of the clinical testing cannot be evaluated reliably. ${ }^{50,51,106}$ Sometimes the apnea test cannot be performed or it must be interrupted by the examiner. Eye injuries may impede an appropriate assessment of pupillary, corneal, or vestibuloreflex testing. In those patients with perforated tympanic membranes iced water caloric irrigation for exploring the vestibulo-ocular reflexes is proscribed. Furthermore, the diagnosis of BD in children and neonates is more complicated and usually ancillary tests are advocated. . $7,98,107-111$

Confirmatory tests are recommended to shorten periods of observation according to physicians' criteria and in those conditions interfering with the clinical BD diagnosis. The Cuban Commission proposed that confirmatory tests should be mandatory in cases of patients with primary brainstem lesions undergoing BD diagnosis. ${ }^{1,49.51}$

Confirmatory tests in BD can be divided into those proving absent $\mathrm{CBF}$ and those that demonstrate loss of bioelectrical activity.

\section{Tests to demonstrate absent cere- bral blood flow}

Bernat recently emphasized that "the most confident way to demonstrate that the global loss of clinical brain functions is irreversible is to show the complete absence of intracranial blood flow." ${ }^{12}$ Ingvar and colleagues defended this, concluding that the permanent cessation of CBF produces total brain infarction. ${ }^{13,114}$

Several tests that can measure CBF accurately and validly in suspected brain-dead patients have been developed in the last decades. The first technique used to demonstrate absence of intracranial circulation in BD distal to the intracranial portions of the internal carotid and vertebral arteries was cerebral angiography. ${ }^{115-117}$ Other techniques used to determine absent CBF have been: cerebral intravenous digital subtraction angiography, intravenous radionuclide angiography, single photon emission tomography (SPECT), echoencephalography, measurement of armto-retina circulation time, ophthalmic artery pressure measurement, xenon-enhanced computed tomography, MRI angiography, CT angiography and CT perfusion, and transcranial Doppler ultrasonography (TCD).

Although it has not been widely used as an ancillary test in BD, the 18F-FDG PET scan has been used by some authors to study brain-dead patients, and confirmed no intracerebral uptake or retention of tracer, consistent with a diffuse absence of brain metabolism. ${ }^{118,119}$

Another technique that could be useful in monitoring biochemical changes in vivo, from coma to $\mathrm{BD}$, is proton magnetic resonance spectroscopy (1H-MRS). N-acetyl aspartate (NAA) content is a measure of neuronal integrity, choline (Cho) content mirrors membrane turnover, and creatine (Cre) relates to energy dependent systems. Falini et al. serially studied a patient with severe global hypoxicischemic brain injury using 1H-MRS. Particularly notable was a quick decline of NAA in the acute phase, suggesting the severity of the neuronal insult, and after seven weeks of evolution the irreversible death of the major part of the neuronal population was confirmed. ${ }^{120}$ We have also applied this technique to monitor metabolic changes in the evolution from a persistent vegetative state to a minimally conscious state. ${ }^{121}$

TCD has been recommended for assessing CBF in suspected brain-dead patients. ${ }^{122-128}$ TCD is a noninvasive technique that measures local blood flow velocity and direction in the proximal portions of large intracranial arteries. TCD requires training and experience to perform it and interpret results; hence, it is typified as operator-dependent. ${ }^{129,130}$ In the ICU setting, intensivists or neurologists usually receive training to apply this technique using portable Doppler devices in suspected brain-dead cases. Oscillating flow, systolic spikes, or no flow patterns are typical Doppler-sonographic flow signals found in the presence of cerebral circulatory arrest, which if irreversible, results in BD. ${ }^{1,131,132}$

Nonetheless, recent reports affirmed that multi-slice CT angiography (CTA) is a robust tool to demonstrate the lack of intracranial blood flow, showing a high sensitivity and a wide safety margin for diagnosing BD. In the near future it might be the preferred test for proving $\mathrm{CBF}^{29,124,133}$

\section{Tests to demonstrate loss of bio- electrical activity}

The EEG has been closely linked to BD since the pioneering descriptions of the death of the nervous system and coma dépassé..$^{134,135}$ The set 
of criteria based on a brainstem standard, like those from the Commonwealth countries, does not include EEG..$^{3-5,136-140}$ On the contrary, EEG is recommended by most countries adopting the "whole brain death" definition. ${ }^{141-145}$

Although EEG is sensitive to hypothermia, drugs, or extreme hypotension, ${ }^{146}$ and several artifacts can appear in the ICU environment, this technique is still extensively used as an ancillary test in BD diagnosis. Buchner et al. proposed that its sensitivity as well as specificity can reach up to $90 \%{ }^{147}$ On the other hand, multimodality evoked potentials (MEP) and electroretinography (ERG) are highly resistant to drug intoxication and hypothermia, and have been shown to be reliable in the ICU environment. ${ }^{188-154}$ Owing to these features, a substantial interest in multimodality evoked potentials (MEPs) in BD has grown over the past two decades, and a wealth of data are now available in the literature. ${ }^{151,152,155-159}$ However, considered as single tests, they have their limitations and they are not included routinely as confirmatory tests for BD diagnosis. ${ }^{1,160}$ Hence, we have proposed to combine EEG, MEP, and ERG in a test battery to study braindead patients in order to increase diagnostic reliability. ${ }^{49,152,158,161-168}$

Therefore, an adequate medical practice would be to assess comatose patients by monitoring $\mathrm{CBF}$ by TCD, and neuronal function by the above mentioned neurophysiologic test battery. If TCD fails to validate the absence of CBF, CTA can be used to confirm BD diagnosis. ${ }^{1}$

\section{Brain death and organ transplants}

Although it is commonly believed that the concept of BD was developed to benefit organ transplants, it evolved independently. Transplantation owed its development to advances in surgery and immunosuppressive treatment; BD owed its origin to the development of intensive care. A historical review demonstrates that the BD concept and organ transplantation arose separately and advanced in parallel, and only began to progress together in the late $1960 \mathrm{~s}^{5-8,11,12,169,170}$ of course, organ procurement programs have induced a tie relationship between organ transplants and BD diagnosis in most countries and, hence, it is extremely important to educate the public to understand that $\mathrm{BD}$ means death of the individual, and of the importance of organ donation for transplants.

\section{Conclusions}

BD should be understood as the ultimate clinical expression of a brain catastrophe leading to a complete and irreversible neurological stoppage, characterized by irreversible coma, absent brainstem reflexes, and apnea. We have enumerated three possible situations for diagnosing death based on the "signs of death". This methodology of diagnosing death does not mean that there are different types of death. The irreversible loss of cardio-circulatory and respiratory functions can cause death only when ischemia and anoxia are prolonged enough to produce an irreversible destruction of the brain.

\section{References}

1. Machado C. Brain death. A reappraisal. New York: Springer 2007;1-223.

2. Pallis C. Brainstem death--the evolution of a concept. Med Leg J 1987;55:84-107.

3. Pallis C. Brainstem death. In: Handbook of Clinical Neurology: Head Injury. Vol 13. Braakman R, ed. Amsterdam: Elsevier Science 1990;441-96.

4. Pallis C. Further thoughts on brainstem death. Anaesth Intensive Care 1995;23: 20-3.

5. Pallis C. Brainstem death: the evolution of a concept. Semin Thorac Cardiovasc Surg 1990;2:135-52.

6. Wijdicks EF. Brain death worldwide: accepted fact but no global consensus in diagnostic criteria. Neurology 2002;58:205.

7. Wijdicks EF. The neurologist and Harvard criteria for brain death. Neurology 2003; 61:970-6.

8. Machado C, Shewmon DL. Brain Death and Disorders of Consciousness. Vol 50. New York: Kluwer Academics/Plenum, 2004;1-268.

9. Machado C. Havana and the coma and death symposia. N Engl J Med 2004;351: 1150-1.

10. Korein J, Machado C. Brain death -Updating a valid concept for 2004. Brain Death and Disorders of Consciousness. 2004;550:1-14.

11. Machado $\mathrm{C}$. The first organ transplant from a brain-dead donor. Neurology 2005; 64:1938-42

12. Machado $\mathrm{C}$. The concept of brain death did not evolve to benefit transplantation. Neurology 2006;66:A2.

13. Machado C, Korein J, Ferrer Y, et al. The concept of brain death did not evolve to benefit organ transplants. J Med Ethics 2007;33:197-200.

14. Machado C. The declaration of Sydney on death. Neurology 2007;68:A6.

15. Landmark article Aug 5, 1968: A definition of irreversible coma. Report of the Ad Hoc Committee of the Harvard Medical School to examine the definition of brain death. J Am Med Assoc 1984;252:677-9.

16. A definition of irreversible coma. Report of the Ad Hoc Committee of the Harvard Medical School to Examine the Definition of Brain Death. J Am Med Assoc 1968;205: 337-40.

17. Walker AE, Molinari GF. Criteria of cerebral death. Trans Am Neurol Assoc 1975; 100:29-35.

18. Robert F, Mumenthaler M. Criteria of brain death. Spinal reflexes in 45 personal studies. Schweiz Med Wochenschr 1977;107:335-41.

19. Cranford RE. Minnesota Medical Association criteria. Brain death: concept and criteria, II. Mo Med 1978;61:600-3.

20. Pasnikowski W. Current criteria of brain death. Przegl Lek 1987;44:672-5.

21. Jan MM. Brain death criteria. The neurological determination of death. Neurosciences 2008;13:350-5.

22. Wijdicks EFM. Clinical Diagnosis and Confirmatory Testing in Brain Death in Adults. In: Brain Death. Wijdicks EFM, ed. Philadelphia: Lippincott Williams \& Wilkins, 2001;61-90.

23. Palmer S, Bader M. Brain tissue oxygenation in brain death. Neurosurgery 2003; 53:831.

24. Palmer S, Bader MK. Brain tissue oxygenation in brain death. Neurocritical Care 2005;2:17-22.

25. Heran MKS, Heran NS, Shemie SD. A review of ancillary tests in evaluating brain death. Can J Neurol Sci 2008;35:409-19.

26. Shimizu N, Shemie S, Miyasaka E, et al. Preliminary report: Use of clinical criteria for the determination of pediatric brain death and confirmation by radionuclide cerebral blood flow. Jpn J Anesthesiol 2000;49:1126-32.

27. Young GB, Shemie SD, Doig CJ, et al. Brief review: the role of ancillary tests in the neurological determination of death. Can J Anaesth 2006;53:620-7.

28. Shemie SD, Lee D, Sharpe M, et al. Brain blood flow in the neurological determination of death: Canadian expert report. Can J Neurol Sci 2008;35:140-5.

29. Escudero D, Otero J, Vega P, et al. Diagnosis of brain death by multislice CT scan: angioCT scan and brain perfusion. Med Intensiva 2007;31:335-41.

30. Kosteljanetz M, Ohrstrom JK, Skjodt S, et al. Clinical Brain-Death with Preserved Cerebral Arterial Circulation. Acta Neurol Scand 1988;78:418-21.

31. Alvarez LA, Lipton RB, Hirschfeld A, et al. Brain death determination by angiography in the setting of a skull defect. Arch 
Neurol 1988:45:225-7.

32. Braun M, Ducrocq X, Huot JC, et al. Intravenous angiography in brain death: Report of 140 patients. Neuroradiology 1997;39:400-5.

33. Hansen AVE, Lavin PJM, Moody EB, et al. False-negative cerebral radionuclide flow study, in brain-death, caused by a ventricular drain. Clin Nucl Med 1993;18: 502-5.

34. van Leusen HJ, Tans JT, Wurzer JA. Hemicraniectomy for treatment of malignant medial cerebral artery infarction in 3 patients. Ned Tijdschr Geneeskd 2001;145:639-43.

35. Pillai A, Menon SK, Kumar S, et al. Decompressive hemicraniectomy in malignant middle cerebral artery infarction: an analysis of long-term outcome and factors in patient selection. J Neurosurg 2007;106:59-65.

36. Palmer S, Bader MK. Cerebral oxygenation. J Neurosurg 2008;108:198-9.

37. Miyazaki Y, Takamatsu H, Tanaka Y, et al. Criteria of cerebral death. Acta Radiol Diagn (Stockh) 1972;13:318-28.

38. Cranford RE. Brain death. Concept and criteria. Minn Med 1978;61:600-3.

39. Cranford RE. Minnesota Medical Association criteria. Brain death: concept and criteria, I. Mo Med 1978;61:561-3.

40. Presidential commission urges states to add brain function criteria to definition of death. Ob Gyn News 1981;16:24-5.

41. Kurdi A, Hijazi H. Criteria of brain death-a review. Middle East J Anesthesiol 1987; 9:149-61.

42. Payen D, Lamer C, Raggueneau JL, et al. Criteria for brain death: cessation of cerebral circulation demonstrated by Doppler ultrasonography of the carotid arteries. Bull Acad Natl Med 1989;173:149-55.

43. Roosen K, Klein M. Criteria and diagnosis of brain death. Versicherungsmedizin 1990;42:110-2.

44. Lang CJ. New criteria for brain death? J Neurol Neurosurg Psychiatry 1991;54: 1030-1.

45. Machado-Curbelo C. A new formulation of death: Definition criteria and diagnostic tests. Rev Neurol 1998;26:1040-7.

46. Zhang TX. [Imminent issues on clinical diagnostic criteria for brain death]. Zhonghua Nei Ke Za Zhi 2004;43:246-8.

47. Wijdicks EFM. Determining Brain-Death in adults. Neurology 1995;45:1003-11.

48. Machado C. Brain formulation of death: A reappraisal. Neurology 1995;45:1097P.

49. Machado C. [Resolution for the determination and certification of death in Cuba]. Rev Neurol 2003;36:763-70.

50. Machado C, Abeledo M, Alvarez C, et al. Cuba has passed a law for the determination and certification of death. Adv Exp Med Biol 2004;550:139-42.
51. Machado C. Determination of death. Acta Anaesthesiol Scand 2005;49:592-3.

52. Machado C. Variability of brain death determination guidelines in leading US neurologic institutions. Neurology 2008; 71:1125.

53. Machado C, García-Tigera J, García 0, et al. Muerte Encefálica. Criterios diagnósticos. Revista Cubana de Medicina 1991;30: 181-206.

54. Machado-Curbelo C. Do we defend a brain oriented view of death. Rev Neurol 2002; 35:387-96.

55. Wijdicks EF. The diagnosis of brain death. N Engl J Med 2001;344:1215-21.

56. de Tourtchaninoff M, Hantson P, Mahieu $\mathrm{P}$, et al. Brain death diagnosis in misleading conditions. Quart J Med 1999;92:40714.

57. Ashwal S. Clinical Diagnosis and Confirmatory Testing of Brain Death in Children. In: Brain Death. Wijdicks EFM, editor. Philadelphia: Lippincott Williams \& Wilkins, 2001, 91-114.

58. Guidelines for the diagnosis of brain death. Canadian Neurocritical Care Group. Can J Neurol Sci 1999;26:64-6.

59. Parker BL, Frewen TC, Levin SD, et al. Declaring pediatric brain death: current practice in a Canadian pediatric critical care unit. Can Med Assoc J 1995;153:90916.

60. Death and brain death: a new formulation for Canadian medicine. Canadian Congress Committee on Brain Death. Can Med Assoc J 1988;138:405-6.

61. Wijdicks EF. The first organ transplant from a brain-dead donor. Neurology 2006; 66:460-1.

62. Matesanz R. The diagnosis of brain death in Latin America. Med Intensiva 2009;33: 413-4.

63. Criteria for the diagnosis of brain stem death. Review by a working group convened by the Royal College of Physicians and endorsed by the Conference of Medical Royal Colleges and their Faculties in the United Kingdom. J R Coll Physicians Lond 1995;29:381-2.

64. An appraisal of the criteria of cerebral death. A summary statement. A collaborative study. J Am Med Assoc 1977;237:9826.

65. Wijdicks EF, Cranford RE. Clinical diagnosis of prolonged states of impaired consciousness in adults. Mayo Clin Proc 2005;80:1037-46.

66. Hansen PB, Thisted BK, Andersen LW, et al. Anesthesiologic aspects of multiorgan donation. Ugeskr Laeger 1992;154:1172-6.

67. Vargas F, Hilbert G, Gruson D, et al. Fulminant Guillain-Barre syndrome mimicking cerebral death: case report and literature review. Intensive Care Med 2000;
26:623-7.

68. Shewmon DA. Recovery from "brain death": a neurologist's apologia. Linacre Q 1997;64:30-96.

69. Bakshi N, Maselli RA, Gospe SM Jr, et al. Fulminant demyelinating neuropathy mimicking cerebral death. Muscle Nerve 1997;20:1595-7.

70. Bohlega SA, Stigsby B, Haider A, et al. Guillain-Barre syndrome with severe demyelination mimicking axonopathy. Muscle Nerve 1997;20:514-6.

71. Coad NR, Byrne AJ. Guillain-Barre syndrome mimicking brainstem death. Anaesthesia 1990;45:456-7.

72. Ostermann ME, Young B, Sibbald WJ, et al. Coma mimicking brain death following baclofen overdose. Intensive Care Med 2000;26:1144-6.

73. Brenner RP. The interpretation of the EEG in stupor and coma. Neurologist 2005;11: 271-84.

74. Marrache F, Megarbane B, Pirnay S, et al. Difficulties in assessing brain death in a case of benzodiazepine poisoning with persistent cerebral blood flow. Hum Exp Toxicol 2004;23:503-5.

75. Sztajnkrycer MD, Huang EE, Bond GR. Acute zonisamide overdose: a death revisited. Vet Hum Toxicol 2003;45:154-6.

76. Caballero F, Lopez-Navidad A, Cotorruelo $\mathrm{J}$, et al. Ecstasy-induced brain death and acute hepatocellular failure: multiorgan donor and liver transplantation. Transplantation 2002;74:532-7.

77. Buylaert WA. Coma induced by intoxication. Acta Neurol Belg 2000;100:221-4.

78. Burkhart KK, Kulig KW. The diagnostic utility of flumazenil (a benzodiazepine antagonist) in coma of unknown etiology. Ann Emerg Med 1990;19:319-21.

79. Walker AE. Cerebral Death. 3rd ed. Baltimore-Munich: Urban \& Schwarzenberg, 1985, 1-198.

80. Saposnik G, Maurino J, Saizar R, et al. Spontaneous and reflex movements in 107 patients with brain death. Am J Med 2005;118:311-4.

81. Wijdicks EFM. Brain Death. Philadelphia: Lippincott Williams \& Wilkins 2001;1-223.

82. Pallis C. ABC of brain stem death. Diagnosis of brain stem death--II. Br Med J (Clin Res Edn) 1982;285:1641-4.

83. Pallis C. ABC of brain stem death. Diagnosis of brain stem death--I. Br Med J (Clin Res Edn) 1982;285:1558-60.

84. Walker AE. Dead or alive. J Nerv Ment Dis 1984;172:639-41.

85. Drory Y, Ouaknine G, Kosary IZ, et al. Electrocardiographic findings in brain death; description and presumed mechanism. Chest 1975;67:425-32.

86. Ouaknine GE, Mercier C. Value of the atropine test in the confirmation of brain 
death]. Union Med Can 1985;114:76-80.

87. Ouaknine GE. Cardiac and metabolic alterations in brain death: discussion paper. Ann NY Acad Sci 1978;315:252-64.

88. Ouaknine G, Kosary IZ, Braham J, et al. Laboratory criteria of brain death. J Neurosurg 1973;39:429-33.

89. Ouaknine G, Kosary IZ, Ziv M. Value of the caloric test and electronystagmography in the diagnosis of irreversible coma. Neurochirurgie 1973;19:407-14.

90. Zhang TX, Shi YJ, Sheng HQ, et al. Clinical diagnosis of 26 cases of brain death. Zhonghua Yi Xue Za Zhi 2004; 84:93-6.

91. Su YY, Zhao H, Zhang Y, et al. Studies on evaluation of brain death. Zhonghua Nei Ke Za Zhi 2004;43:250-3.

92. Goila AK, Pawar M. The diagnosis of brain death. Indian J Crit Care Med 2009;13:711.

93. Huttemann E, Schelenz C, Sakka SG, et al. Atropine test and circulatory arrest in the fossa posterior assessed by transcranial Doppler. Intensive Care Med 2000;26: 422-5.

94. Goetting MG, Contreras E. Systemic atropine administration during cardiac arrest does not cause fixed and dilated pupils. Ann Emerg Med 1991;20:55-7.

95. Cardan C, Roth A, Biro J. The atropine test in the assessment of brain death. Rev Chir Oncol Radiol 0 R L Oftalmol Stomatol Chir 1983;32:393-7.

96. Wijdicks EF, Manno EM, Holets SR. Ventilator self-cycling may falsely suggest patient effort during brain death determination. Neurology 2005;65:774.

97. Lang CJ, Heckmann JG. Apnea testing for the diagnosis of brain death. Acta Neurol Scand 2005;112:358-69.

98. Tsai WH, Lee WT, Hung KL. Determination of brain death in children-- a medical center experience. Acta Paediatr Taiwan 2005;46:132-7.

99. Burns JM, Login IS. Confounding factors in diagnosing brain death: a case report. BMC Neurol 2002;2:5.

100. Melano R, Adum ME, Scarlatti A, et al. Apnea test in diagnosis of brain death: comparison of two methods and analysis of complications. Transplant Proc 2002; 34:11-2.

101. Vivien B, Haralambo MS, Riou B. Barotrama during apnea testing for the determination of brain death. Ann Fr Anesth Reanim 2001;20:370-3.

102. Jeret JS. Complications during apnea testing in the determination of brain death: predisposing factors. Neurology 2001;56:1249.

103. Rigg CD, Cruickshank S. Carbon dioxide during and after the apnoea test--an illustration of the Haldane effect. Anaesthesia
2001;56:377.

104. Lessard M, Mallais R, Turmel A. Apnea test in the diagnosis of brain death. Can J Neurol Sci 2000;27:353-4.

105. Goudreau JL, Wijdicks EF, Emery SF. Complications during apnea testing in the determination of brain death: predisposing factors. Neurology 2000;55:1045-8.

106. Machado C. National Commission for the Determination and Certification of Death. Resolution for the determination and certification of death in Cuba. Rev Neurol 2003;36:763-70.

107. Okuyaz C, Gucuyener K, Karabacak NI, et al. Tc-99m-HMPAO SPECT in the diagnosis of brain death in children. Pediatr Int 2004;46:711-4.

108. Mejia RE, Pollack MM. Variability in brain death determination practices in children. J Am Med Assoc 1995;274:550-3.

109. Paret G, Barzilay Z. Apnea testing in suspected brain dead children--physiological and mathematical modelling. Intensive Care Med 1995;21:247-52.

110. Chantarojanasiri T, Preutthipan A. Apnea documentation for determination of brain death in Thai children. J Med Assoc Thai 1993;76:165-8.

111. Galaske RG, Schober 0, Heyer R. Determination of brain death in children with 123I-IMP and Tc-99m HMPAO. Psychiatry Res 1989;29:343-5.

112. Bernat JL. On irreversibility as a prerequisite for brain death determination. Adv Exp Med Biol 2004;550:161-7.

113. Ingvar DH, Widen L. [Brain death. Summary of a symposium]. Lakartidningen 1972;69:3804-14.

114. Ingvar DH. Brain death--total brain infarction. Acta Anaesthesiol Scand Suppl 1971;45:129-40.

115. Bucheler E, Kaufer C, Dux A. Cerebral angiography to determine brain death. Fortschr Geb Rontgenstr Nuklearmed 1970;113:278-96.

116. Matricali B. Intracranial circulatory arrest. Minerva Neurochir 1970;14:267.

117. Allais B, Vlahowitch, Du C, et al. Angiographic criteria of brain death. Anesth Analg (Paris) 1971;28:843-57.

118. Meyer MA. Evaluating brain death with positron emission tomography: case report on dynamic imaging of $18 \mathrm{~F}$-fluorodeoxyglucose activity after intravenous bolus injection. J Neuroimaging 1996; 6:117-9.

119. Laureys S, Owen AM, Schiff ND. Brain function in coma, vegetative state, and related disorders. Lancet Neurol 2004; 3:537-46.

120. Falini A, Barkovich AJ, Calabrese G, et al. Progressive brain failure after diffuse hypoxic ischemic brain injury: a serial MR and proton MR spectroscopic study.
Am J Neuroradiol 1998;19:648-52.

121. Machado C, Rodriguez R, Carballo M, et al. Results of Proton MRS Studies in PVS and MCS Patients. Can J Neurol Sci 2009;36:365-9.

122. Jonkman EJ, Mosmans PC. Doppler haematotachography: problems in interpretation and new applications. Clin Neurol Neurosurg 1977;80:33-45.

123. Machado C. Assessment: Transcranial Doppler ultrasonography: Report of the Therapeutics and Technology Assessment Subcommittee of the American Academy of Neurology. Neurology 2004;63:2457-8.

124. Stulin ID, Sinkin MV. Current clinical and instrumental diagnosis of brain death. Zh Nevrol Psikhiatr Im S S Korsakova 2006; 106:58-64.

125. Young GB, Shemie SD, Doig CJ, et al. Brief review: the role of ancillary tests in the neurological determination of death. Can J Anaesth 2006;53:620-7.

126. Sardinha LAC, Araujo S, Boin IFSF. Brain death and transcranial Doppler ultrasound as exam for confirming test and its applicability in potential donors. Transpl Int 2007;20:346.

127. Calderon CV, Portela PC. Recommendations of the transcranial Doppler in the diagnosis of brain death. Neurologia 2008;23:397-8.

128. Conti A, Iacopino DG, Spada A, et al. Transcranial doppler ultrasonography in the assessment of cerebral circulation arrest: improving sensitivity by trancervical and transorbital carotid insonation and serial examinations. Neurocritical Care 2009;10:326-35.

129. Perez-Nellar J, Scherle C, Machado C. TCD systolic spikes in a malignant MCA infarct. Neurocrit Care 2009;11:94-6.

130. Sloan MA, Alexandrov AV, Tegeler CH, et al. Assessment: transcranial Doppler ultrasonography: report of the Therapeutics and Technology Assessment Subcommittee of the American Academy of Neurology. Neurology 2004;62:1468-81.

131. Martinelli 0, Benedetti-Valentini F. Trancranial Doppler: value in clinical practice. Int Angiol 2009;8:249-53.

132. Escudero D. [Brain death diagnosis]. Med Intensiva 2009;33:185-95.

133. Greer DM, Strozyk D, Schwamm LH. False positive CT angiography in brain death. Neurocritical Care 2009;11:272-5.

134. Wertheimer P, Jouvet M, Descotes J. Diagnosis of death of the nervous system in comas with respiratory arrest treated by artificial respiration. Presse Med 1959;67:87-8.

135. Mollaret P, Goulon M. Coma dépassé (preliminary memoir). Rev Neurol (Paris) 1959;101:3-15.

136. Pallis C. Danish ethics council rejects 
brain death as the criterion of death -commentary 2: return to Elsinore. J Med Ethics 1990;16:10-3.

137. Connie F0, Kelvin LK, Chung AC, et al. Knowledge, acceptance and perception towards brainstem death among medical students in Hong Kong: a questionnaire survey on brainstem death. Med Teach 2008;30:e125-30.

138. Pallis C. Defining death. Br Med J (Clin Res Ed) 1985;291:666-7.

139. Pallis C. ABC of brain stem death. The arguments about the EEG. Br Med J (Clin Res Ed) 1983;286:284-7.

140. Rodin E, Tahir S, Austin D, et al. Brainstem death. Clin Electroencephalogr 1985;16:63-71.

141. Bernat JL, Culver CM, Gert B. On the definition and criterion of death. Arch Intern Med 1981;94:389-94.

142. Bernat JL, Culver CM, Gert B. Definition of death. Ann Intern Med 1981;95:652.

143. Bernat JL. The biophilosophical basis of whole-brain death. Soc Philos Policy 2002;19:324-42.

144. Bohatyrewicz R, Bohatyrewicz A, Zukowski M, et al. Reversal to wholebrain death criteria after 15-year experience with brainstem death criteria in Poland. Transplant Proc 2009;41:2959-60.

145. Bernat JL. The concept and practice of brain death. Prog Brain Res 2005;150: 369-79.

146. Chatrian GE. Electrophysiologic evaluation of brain death: A critical appraisal. In: Electrodiagnosis in Clinical Neurology. Aminoff MJ, ed. New York: Churchill Livingstone, 1980;525-88.

147. Buchner H, Schuchardt V. Reliability of electroencephalogram in the diagnosis of brain death. Eur Neurol 1990;30:138-41.

148. Cobb WA, Dawson GD. The latency and form in man of the occipital potentials evoked by bright flashes. J Physiol 1960; 152:108-21.

149. Neumann N, Kotchoubey B. Assessment of cognitive functions in severely paralysed and severely brain-damaged patients: neuropsychological and electrophysiological methods. Brain Res Protoc 2004;14:25-36.

150. Rothstein TL. Recovery from near death following cerebral anoxia: A case report demonstrating superiority of median somatosensory evoked potentials over EEG in predicting a favorable outcome after cardiopulmonary resuscitation. Resuscitation 2004;60:335-41.

151. Facco E, Machado C. Evoked potentials in the diagnosis of brain death. Adv Exp Med Biol 2004;550:175-87.

152. Machado C. Evoked potentials in brain death. Clin Neurophysiol 2004;115:238-9.

153. Guerit JM. Evoked potentials in severe brain injury. Prog Brain Res 2005;150: 415-26.

154. Wang K, Yuan Y, Xu ZQ, et al. Benefits of combination of electroencephalography, short latency somatosensory evoked potentials, and transcranial Doppler techniques for confirming brain death. $\mathrm{J}$ Zhejiang University-Sci B 2008;9:916-20.

155. Sasaki M, Sakamoto T, Yamashita M, et al. Auditory evoked brain-stem responses (ABRs) in brain dead status. No To Shinkei 1984;36:917-24.

156. Borel C, Hanley D. Neurologic intensive care unit monitoring. Crit Care Clin 1985;1:223-39.

157. Erbengi A, Erbengi G, Cataltepe 0, et al. Brain death: determination with brain stem evoked potentials and radionuclide isotope studies. Acta Neurochir (Wien) 1991;112:118-25.

158. Machado C, García-Tigera J, Coutin P. Multimodality evoked potentials and electroretinography in a test battery for the early diagnosis of brain death. Electroenceph Clin Neurophysiol 1991;79: S19.

159. Su YY, Yang QL, Pang Y, et al. Evaluation of coma patients after cardiopulmonary resuscitation. Chin Med J (Engl)
2005;118:1808-11.

160. Machado-Curbelo C, Roman-Murga JM. Usefulness of multimodal evoked potentials and the electroretinogram in the early diagnosis of brain death. Rev Neurol 1998;27:809-17.

161. Machado C, Pumariega J, García-Tigera J, et al. A multimodal evoked potential and electroretinography test battery for the early diagnosis of brain death. Int $\mathrm{J}$ Neurosci 1989;49:241-2.

162. Machado C. Visual evoked potentials and electroretinography in brain-dead patients. Neurophysiologie Clinique 1990;20:18s.

163. Machado C, Valdes P, Garciatigera J, et al. Brain-Stem Auditory Evoked-Potentials and Brain-Death. Electroencephalogr Clin Neurophysiol 1991;80:392-8.

164. Machado C. Multimodality evoked potentials and electroretinography in a test battery for an early diagnosis of brain death. J Neurosurg Sci 1993;37:125-31.

165. Machado C, Santiesteban R, Garcia 0, et al. Visual evoked potentials and electroretinography in brain-dead patients. Doc Ophthalmol 1993;84:89-96.

166. Machado C. Brain death diagnosis. Acta Medica Medianae 2009;48:41-6.

167. Machado C, Valdes P, Garcia 0, et al. Short latency somatosensory evoked potentials in brain-dead patients using restricted low cut filter setting. J Neurosurg Sci 1993;37:133-40.

168. Machado-Curbelo C. A new formulation of death: definition, criteria and diagnostic tests. Rev Neurol 1998;26:1040-7.

169. Machado C. The first organ transplant from a brain-dead donor - Reply. Neurology 2006;66:461.

170. Machado C, Korein J. Neuropathology of brain death in the modern transplant era. Neurology 2009;72:1028. 